\title{
Optimal management of pediatric obsessive-compulsive disorder
}

This article was published in the following Dove Press journal:

Pediatric Health, Medicine and Therapeutics

2 May 2012

Number of times this article has been viewed

\author{
Danielle Ung' \\ Chelsea $\mathrm{MAle}^{2}$ \\ Eric A Storch ${ }^{1-3}$ \\ 'Department of Psychology, \\ ${ }^{2}$ Department of Pediatrics, \\ ${ }^{3}$ Department of Psychiatry and \\ Behavioral Neuroscience, University \\ of South Florida, Tampa, FL, USA
}

\begin{abstract}
The last two decades have seen an increase in evidence supporting behavioral and pharmacologic treatments of pediatric obsessive-compulsive disorder, a debilitating anxiety disorder that affects about $1 \%$ of youth. However, dissemination of knowledge about these treatments to pediatric health care providers and families of affected children has been less successful. Following best practice guidelines, specific evidence for cognitive-behavioral therapy with exposure and response prevention and pharmacotherapy with serotonin reuptake inhibitors are presented. A discussion of clinical features and their impact on treatment delivery and empirically based suggestions for overcoming these barriers are also presented. Future directions for enhancing treatment implementation and dissemination are discussed.
\end{abstract}

Keywords: obsessive-compulsive disorder, children, treatment, cognitive-behavioral therapy, serotonin reuptake inhibitors, antidepressant medication

\section{Introduction}

Pediatric obsessive-compulsive disorder (OCD) is a chronic, disabling anxiety disorder characterized by obsessions and/or compulsions that are associated with significant distress and/or interference in functioning of daily life. ${ }^{1}$ Obsessions are recurring, upsetting intrusive thoughts or images that cause disabling distress. Common obsessions include fears of contamination, sexual behavior (eg, fears of doing something sexually inappropriate), aggressiveness (eg, fears of harming another person or their self), or religious taboos (eg, concerns about committing blasphemy or offending a religious figure); and symmetry/exactness and hoarding/saving obsessions. ${ }^{2,3}$ The distressing nature of obsessions motivates compulsions, which are repetitive, overt or covert behaviors performed to temporarily relieve the angst associated with obsessions. Common compulsions include cleaning, checking, repeating behaviors, reassurance seeking, covert rituals (eg, counting, praying), and hoarding/collecting. ${ }^{2,4,5}$ Unlike adults with OCD, children are not required to have insight into their obsessive-compulsive symptoms, ${ }^{1}$ although most children have some degree of insight. ${ }^{6,7}$

\section{Prevalence}

Clinically significant obsessive-compulsive symptoms occur in about $1 \%$ of children and adolescents, ${ }^{8,9}$ with as many as $4 \%$ of youth exhibiting subclinical symptoms. ${ }^{10}$ Nearly $80 \%$ of adult OCD cases have initial onset in childhood, ${ }^{11,12}$ which typically runs a protracted course without the initiation of appropriate treatment. The sex distribution of childhood OCD is approximately 3:2 of boys to girls, which is due in
Correspondence: Eric A Storch 800 6th Street South, 4th Floor North, Box 7523, St Petersburg,

FL 3370I, USA

Tel +l 7277678230

Fax +I 7277677786

Email estorch@health.usf.edu
(C) 2012 Ung et al, publisher and licensee Dove Medical Press Ltd. This is an Open Access article which permits unrestricted noncommercial use, provided the original work is properly cited. 
part to a higher frequency of tic disorders in boys. ${ }^{2}$ However, the sex ratio roughly equalizes by adolescence/ early adulthood. ${ }^{3,13}$

\section{Impairment}

The scope of impairment associated with OCD is unique among the anxiety disorders ${ }^{14}$ due to the time occupied by and distress associated with symptoms, avoidance, and psychiatric comorbidity. ${ }^{15}$ Youth with OCD experience significant impairment in school, home, and family functioning, ${ }^{16-18}$ and reduced quality of life. ${ }^{19}$ Specific domains of impairment noted include impaired functioning in school/academic domains (eg, getting to school/class on time, reading, listening, concentrating on schoolwork, doing homework, and taking tests), home life (eg, getting dressed, getting ready for bed, bathing/grooming, and watching television/ listening to music), and social relationships (eg, difficulty making new friends, going to movies, and eating in public places). ${ }^{16}$ For example, a child may spend hours and hours redoing otherwise simple homework assignments due to the compulsion to write and rewrite letters, words, and sentences on writing assignments.

\section{Assessment}

Clinicians should routinely screen for the presence of obsessions and/or compulsions or repetitive behaviors in children and adolescents during clinical interviews with the family and utilize simple probing questions. For example, when probing for questions regarding obsessions, a clinician may ask, "Do you have worries that just won't go away even when you want them to stop, such as having concerns about germs or chemicals, having thoughts over and over of bad things happening to yourself or others, or worries about having to do things correctly?" When probing for compulsions, a clinician may ask, "Do you do things over and over or have habits you can't stop, such as washing your hands, checking things, touching objects the same number of times, feeling that you have to tell on yourself repeatedly, or always asking if you did the right thing or did it correctly?"20 If screening questions suggest that obsessive-compulsive symptoms may be present, further probes should be conducted in the interview and/or with psychometrically sound measures that assess the time occupied by the symptoms, and the level of distress and functional impairment (eg, the Children's Yale-Brown Obsessive Compulsive Scale). ${ }^{21}$ Furthermore, a full psychiatric evaluation is needed to assess mental status, comorbid disorders, and medical/family/developmental/ school history to assess fully the clinical presentation, health status, and possible factors that may complicate treatment outcome. $^{21}$

In order to inform differential treatment when assessing OCD symptoms, clinicians should be aware of important differences between obsessions versus developmentally normative worries, and OCD symptoms versus other psychiatric conditions such as tic disorders. For example, unlike OCD symptoms, tics are sudden, repetitive, stereotyped motor movements or phonic productions that may appear voluntary, which can be distinguished from OCD symptoms by their relative brevity, lack of purpose, and typically involuntary nature. It is critical that clinicians are able to differentiate the two conditions, because each condition has unique recommended practice guidelines for treatment.

\section{Pediatric acute-onset neuropsychiatric syndrome}

While assessing for the presence of obsessive-compulsive symptoms, clinicians should be aware of a subgroup of children with OCD who experience abrupt, dramatic onset of significantly severe and distressing obsessive-compulsive symptoms or severely restricted food intake which does not follow the pattern of gradual onset typically seen in youth with OCD known as Pediatric Acute-onset Neuropsychiatric Syndrome (PANS). These youths also exhibit additional neuropsychiatric symptoms (eg, anxiety, emotional lability and/or depression, irritability, aggression and/or severely oppositional behaviors, developmental regression, rigid or repetitive behaviors, tics, worsening fine motor skills, and compulsive urination) and show a marked deterioration in school performance and adaptive functioning. ${ }^{22,23}$ Furthermore, symptom onset in a subgroup of these children is associated with an infectious trigger. Youth with PANDAS (Pediatric Autoimmune Neuropsychiatric Disorders Associated with Streptococcal infections) have prepubertal, acute onset of episodic (relapse-remitting) obsessivecompulsive symptoms or tics that have a temporal association with Group A streptococcal infections. ${ }^{25}$ They also display neurologic abnormalities such as motor hyperactivity and choreiform movements. ${ }^{22-25}$ In comparison, youth who display obsessive-compulsive symptoms or tics after any infection, not limited to Group A streptococcal infections, are broadly characterized as having PITANDS (Pediatric Infection-triggered Autoimmune Neuropsychiatric Disorders) with sudden, recurrent, prepubertal clinically significant obsessive-compulsive and/or tic symptoms that are triggered or exacerbated by a bacterial or viral infection (eg, influenza, varicella, Group A streptococcus). ${ }^{25}$ Although evidence for the neuropsychiatric syndromes based on infections is not without controversy, and 
definitive data do not exist at this time regarding treatment for PANS, clinicians should treat infections in the child as dictated by pediatric practice guidelines. Preliminary data and clinical accounts suggest that immune-targeted therapies, including acute antibiotic treatment, intravenous immunoglobulin, and plasmapheresis, may show efficacy in treating obsessivecompulsive symptoms. ${ }^{26,27}$ There are also some data suggesting that cognitive-behavioral therapy (CBT) may be effective. ${ }^{28,29}$ Collectively, these treatment data are preliminary, and more rigorous testing is required to determine conclusive treatment guidelines for PANS.

\section{Treatment}

Two treatments have demonstrated empirical support for the treatment of pediatric OCD, ie, CBT with exposure and response prevention (see Table 1 for a summary of randomized controlled CBT trials) and pharmacotherapy (serotonin reuptake inhibitors, including selective serotonin reuptake inhibitors and the tricyclic antidepressant, clomipramine. See Table 2 for a summary of randomized, placebo-controlled trials). CBT has demonstrated larger treatment effects $(d=1.45-1.98)$ than serotonin reuptake inhibitor monotherapy $(d=0.48-1.13),{ }^{30,31}$ and boasts greater symptom reduction (53\%-65\% versus $26 \%-30 \%$ as measured by the Children's Yale-Brown Obsessive Compulsive Scale) $)^{32,33}$ and remission levels $(24 \%-82 \%$ versus $10 \%-45 \%) .{ }^{32,34-37}$ Given this evidence, expert consensus guidelines recommend that children with OCD should first be treated with CBT alone for mild and moderate cases, or together with serotonin reuptake inhibitor therapy for severe presentations..$^{20,38}$

\section{Cognitive-behavioral therapy}

CBT for OCD typically incorporates three components, ie, psychoeducation, exposure and response prevention (ie, presentation of the feared stimuli while resisting engaging in compulsions), and cognitive therapy. ${ }^{39} \mathrm{CBT}$ for OCD is typically delivered weekly over the course of 12-14 weeks but can be applied in an intensive treatment format (ie, daily psychotherapy sessions) with comparable efficacy in both specialty clinics and traditional outpatient settings. ${ }^{40}$ Clinicians begin CBT by educating parents and children about the nature of OCD and its treatment. The child is taught to identify and understand his/her anxiety symptoms and why treatment is necessary. To convey the treatment rationale at a developmentally appropriate level, clinicians often use metaphors (eg, "OCD is like a bully who makes you do things you do not want to do"), visual imagery (eg, "imagine how scared you felt when you watched your first scary movie. Now imagine watching the movie 100 times. You will probably feel less scared than when you watched the movie the first time. This is similar to exposure therapy. You face your fears numerous times and over time, your anxiety will go down"), or other examples to help make OCD more concrete. ${ }^{35,41}$

The cognitive portion of treatment involves identifying and challenging obsessional thoughts and replacing them with more realistic thoughts in a developmentally appropriate manner. For example, a child who experiences obsessions about contracting an illness if $\mathrm{s} /$ he touches a door knob might be encouraged to think about all the times when other people touch door knobs and do not get sick. Other cognitive tools, such as reframing OCD as something outside of the child (ie, externalizing OCD) and "bossing back" OCD (ie, having children tell OCD that they do not have to complete compulsions to make anxiety dissipate) may help children resist symptoms. $^{35,39}$

Exposure with response prevention is the primary component of CBT and is based on the behavioral theory that anxiety is maintained by both classical and operant conditioning. ${ }^{42}$ Through a combination of verbal transmission, direct conditioning, social learning, prior conditioning, and/or genetic factors, ${ }^{43}$ neutral ideas or images are paired with feelings of heightened arousal (eg, anxiety) that motivate rituals which temporarily relieve distress. As a result, the rituals are maintained through a process known as negative reinforcement. In treatment, the child is gradually exposed to distress-provoking stimuli through the use of a stimulus hierarchy and prevented from engaging in the compulsion that would allow anxiety/distress to reduce naturally over time. ${ }^{41}$ Children and their families are then assigned specific exposure tasks to conduct as homework to practice and generalize the skills learned in the clinical setting to the outside environment. Family involvement is central to reinforce treatment goals, promote generalization, and reduce family accommodating behaviors. ${ }^{44,45}$

\section{Pharmacotherapy}

In clinical trials, four selective serotonin reuptake inhibitors (paroxetine, fluoxetine, fluvoxamine, and sertraline) and a tricyclic antidepressant (clomipramine) have demonstrated efficacy relative to placebo in the treatment of pediatric OCD (see Table 2). Only fluoxetine (age 7 years and older, 10-60 mg/day), fluvoxamine (age 8 years and older, 25-200 mg/day), sertraline (age 6 years and older, 25-200 mg/day), and clomipramine (age 10 years and older, 25-200 mg/day) are approved by the Food and 


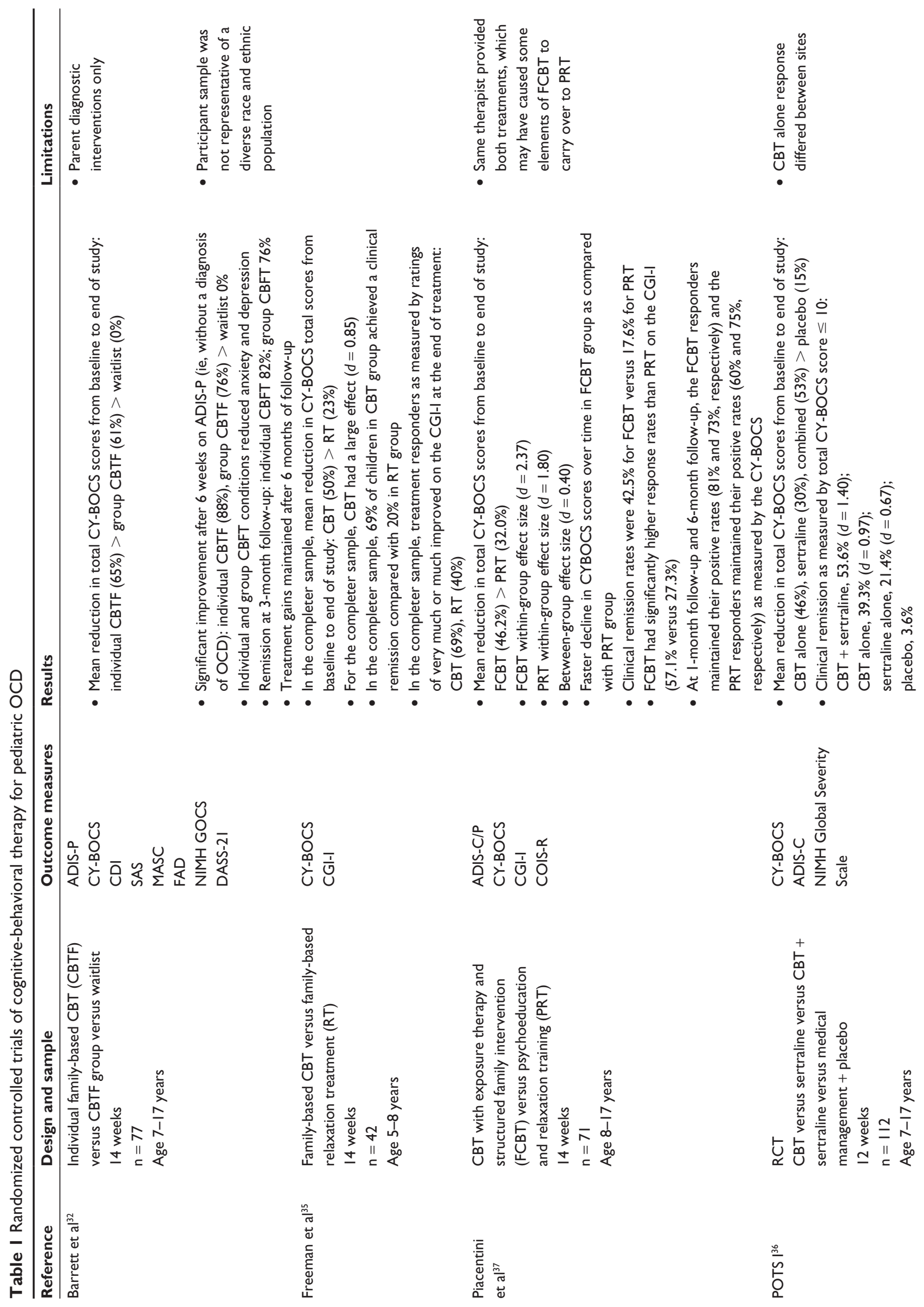



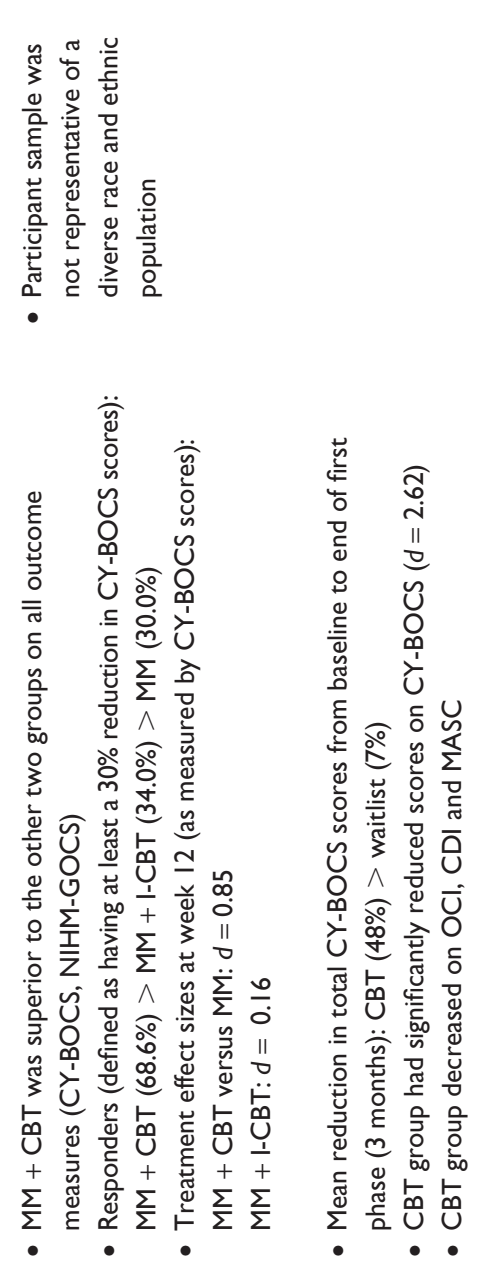

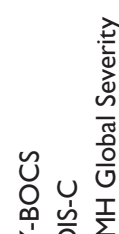
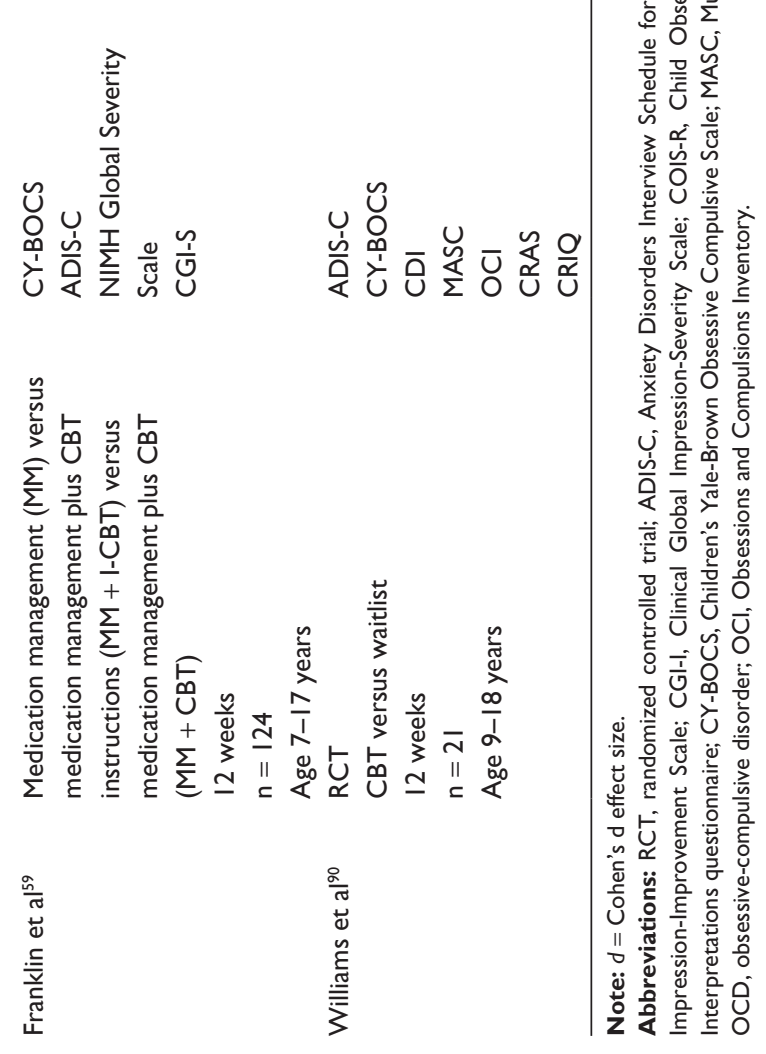

Drug Administration (FDA) for the treatment of pediatric OCD (United States FDA Center for Drug Evaluation and Research, personal communication, December 28, 2011). In a meta-analysis, Geller et a ${ }^{47}$ examined study designs, outcome measures, and medication efficacy across 12 clinical trials of selective serotonin reuptake inhibitors (paroxetine, fluvoxamine, fluoxetine, and sertraline) and clomipramine, finding a modest aggregate effect size relative to placebo $(d=0.46 ; 95 \%$ confidence interval $0.37-0.55)$. Clomipramine was significantly more effective in reducing obsessivecompulsive symptoms than paroxetine, fluvoxamine, fluoxetine, and sertraline, which were not significantly different from one another. However, clomipramine is not recommended as the first line of pharmacotherapeutic treatment for pediatric OCD due to side effects (eg, dry mouth, dizziness, fatigue, tremors, and cardiac complications)..$^{20,46,47}$

Pharmacologic monotherapy typically demonstrates a $30 \%-40 \%$ reduction in obsessive-compulsive symptoms, ${ }^{36,47}$ leaving many youth with clinically significant residual symptoms. ${ }^{47-49}$ Symptom remission rates for children treated with serotonin reuptake inhibitors alone are modest but positive, with one study finding only $21.4 \%$ of children no longer meeting criteria for OCD. ${ }^{36}$ While generally safe, serotonin reuptake inhibitors are associated with some adverse effects eg, headaches, abdominal pain, nausea, fatigue, and somnolence, ${ }^{51-53}$ most notably, concern about behavioral activation resulted in a black box warning requiring physicians to monitor serotonin reuptake inhibitor usage carefully due to reports of increased risk of suicidal ideation and suicidal-like behaviors. $^{54-57}$

\section{Augmenting agents}

Between $40 \%$ and $70 \%$ of OCD patients treated with a serotonin reuptake inhibitor alone do not respond adequately to treatment, ${ }^{49,52,58-60}$ and full symptom remission from serotonin reuptake inhibitor monotherapy is infrequent. ${ }^{36,49,50}$ An adequate dose of serotonin reuptake inhibitor therapy is defined as a minimum of 10 weeks of serotonin reuptake inhibitor therapy at maximum recommended or maximum tolerated doses, with no change in dose for the preceding three weeks. Adequate dose for CBT is defined as at least 10 sessions, which includes at least eight sessions of exposure/response prevention. ${ }^{20}$ Patients who remain symptomatic after adequate serotonin reuptake inhibitor intervention are often augmented with off-label atypical antipsychotic medications, but systemic efficacy data are lacking. Although few experimental studies exist, case reports and open trials of augmenting agents have reported benefit (clonazepam, ${ }^{61}$ 


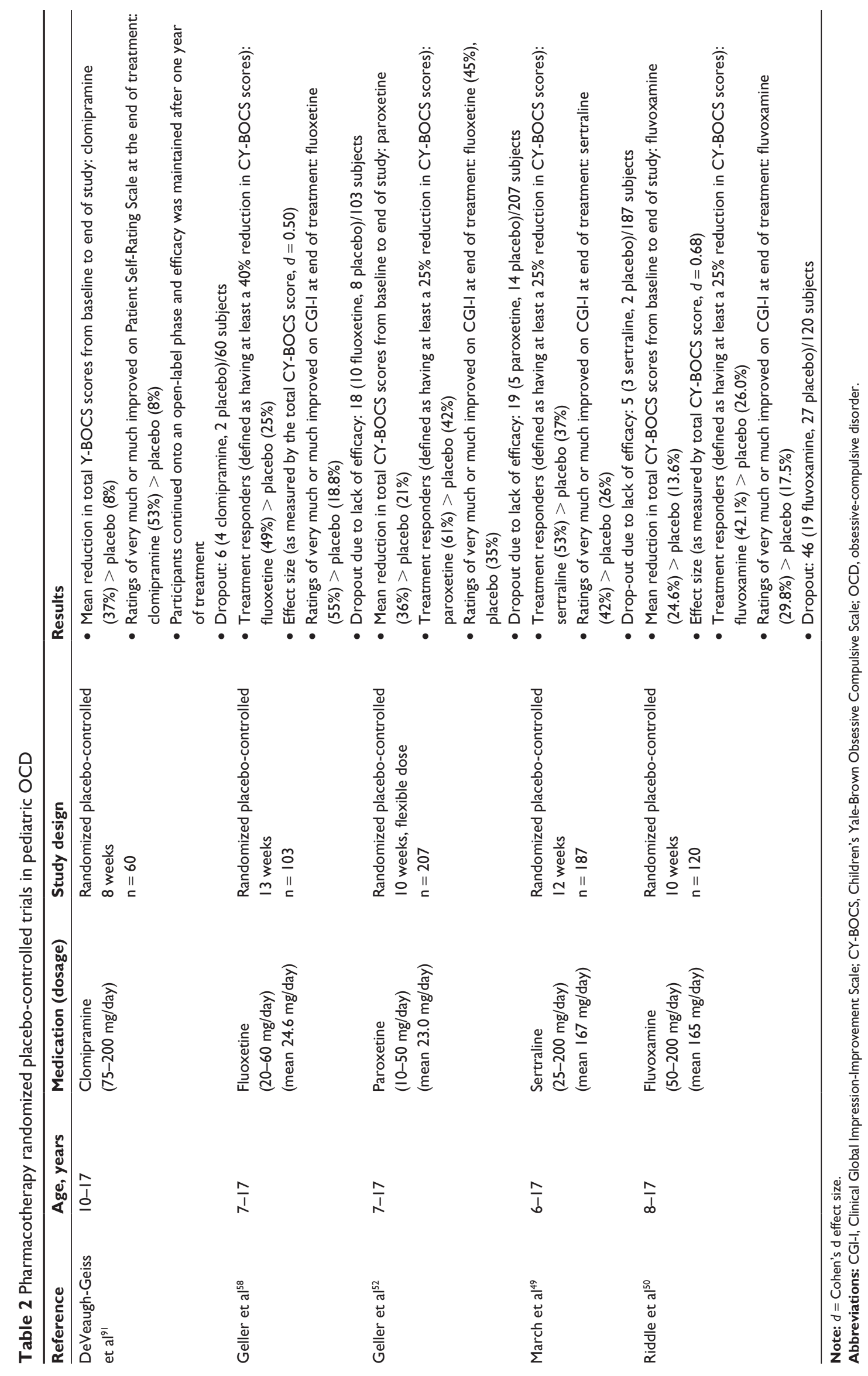


risperidone, ${ }^{62}$ haloperidol, ${ }^{63}$ aripiprazole,${ }^{64}$ and riluzole ${ }^{65}$ ). However, these medications have been associated with adverse effects (eg, excessive sedation, dizziness, increased appetite, weight gain $)^{61,63,65-67}$ and their off-label use should only be considered after other more safe and tolerable alternatives have been tried. ${ }^{68}$ To this end, recent data indicate the efficacy of CBT augmentation for youth with OCD who only partially respond to SRIs..$^{59}$

\section{Factors that influence treatment outcomes}

There are multiple factors that may contribute to the efficacy and sustainability of positive treatment outcomes, such as family accommodation, insight and motivation, and comorbidity.

\section{Family accommodation}

Many family members accommodate their child's obsessivecompulsive symptoms (eg, providing objects for rituals, following routines to minimize anxiety, providing extra assistance with homework and chores, providing reassurance) to minimize their child's distress and to decrease symptom-related impairment. ${ }^{44}$ Although well intentioned, accommodation maintains obsessive-compulsive symptoms in the same way as rituals (eg, anxiety reduction) and prevents the child from learning that the feared consequences usually do not occur, resulting in greater impairment, symptom severity, and negative family dynamics. ${ }^{44,69,70}$ Furthermore, family accommodation can serve as a treatment barrier, preventing the child from experiencing the natural habituation of anxiety and reinforcing obsessivecompulsive symptoms. ${ }^{71,72}$

\section{Insight and motivation}

Children with poor insight and low motivation may not respond optimally to treatment due to limited symptom resistance and poor adherence to treatment recommendations (eg, taking medication, participating in CBT) ${ }^{67,73}$ Poor insight is associated with more severe obsessive-compulsive symptoms, higher levels of internalizing behaviors, greater impairment in school, social, and family contexts, and poor treatment response to CBT and pharmacotherapy. ${ }^{7,67,71,74,75}$ For children who refuse or have low motivation to engage in CBT, medication treatment may be considered. ${ }^{20}$ Behavioral approaches to increase a child's motivation to continue treatment include the creation of a reward program early in treatment ${ }^{20,35}$ and CBT supplemented with motivational interviewing. ${ }^{76}$ Motivational interviewing is a therapeutic intervention used to decrease ambivalence and promote motivation to change one's behavior. It may be particularly helpful for youth who may be less willing to follow instructions or lack the self-confidence to engage in exposures in and outside of the sessions. ${ }^{76}$

\section{Comorbidity}

Comorbid conditions are common in children with OCD, with about $74 \%-80 \%$ meeting criteria for another psychiatric illness. ${ }^{77-79}$ In addition to being directly related to a more severe clinical presentation, comorbid conditions interfere with treatment outcome. In CBT, comorbid conditions may reduce treatment adherence and participation in sessions..$^{78,80-82}$ Furthermore, comorbid disorders can adversely affect response rates to serotonin reuptake inhibitors and result in greater rates of relapse..$^{81,83,84}$ With paroxetine, for example, the full sample response rate of $71 \%$ decreased significantly when examining responses for comorbid subgroups (attention deficit/hyperactivity disorder, 56\%; chronic tic disorder, $53 \%$; oppositional defiant disorder, $39 \%) .{ }^{83}$ Consequently, a child who has a comorbid condition such as major depression, disruptive behavior disorder, or attention deficit hyperactivity disorder may require a different treatment approach considering how the comorbid disorder might affect presentation and/or treatment course..$^{20,82,85-87}$ For example, if depression could impact the course of treatment, sequentially providing evidence-based depression therapies (eg, antidepressant medication, CBT, or interpersonal psychotherapy) may be indicated. Similarly, those with uncontrolled attention deficit hyperactivity disorder may benefit from concurrent pharmacologic intervention. ${ }^{88}$

\section{Conclusion}

Pediatric OCD is an impairing disorder that runs a chronic course without treatment. For mild to moderate cases of pediatric OCD, CBT is recommended as the first line of treatment. For moderate to severe cases of pediatric OCD, serotonin reuptake inhibitor medication in addition to CBT is recommended. ${ }^{20}$ However, as discussed in this review, treatment may vary on a case-by-case basis dependent upon factors such as family accommodation, insight, motivation, and comorbidity. Clinical indications that signal a need for a higher level of care (ie, intensive or residential OCD-specific care) include limited response to past treatments, persisting lack of motivation and insight, and severe symptomology. ${ }^{20}$ Although CBT is recommended per established guidelines, dissemination of these guidelines is lagging. ${ }^{20}$ Fewer than $10 \%$ of adults being treated with CBT receive CBT with exposure therapy, ${ }^{89}$ although this has greatly improved over 
the past decade. While both CBT and the serotonin reuptake inhibitors demonstrate efficacy, many youth are partial responders; thus, future efforts need to examine innovative methods for maximizing treatment outcomes and remission rates, as well as examining treatment moderators to individualize treatment.

\section{Disclosure}

The authors report no conflicts of interest in this work.

\section{References}

1. American Psychiatric Association. Diagnostic and Statistical Manual of Mental Disorders, 4th ed. Washington, DC: American Psychiatric Press; 2000.

2. Geller DA, Biederman J, Jones J, Shapiro S, Schwartz S, Park KS. Obsessive-compulsive disorder in children and adolescents: a review. Harv Rev Psychiatry. 1998;5:260-273.

3. Tukel R, Ertekin E, Batmaz S, et al. Influence of age of onset on clinical features in obsessive-compulsive disorder. Depress Anxiety. $2005 ; 21: 112-117$

4. Masi G, Millepiedi S, Perugi G, et al. A naturalistic exploratory study of the impact of demographic, phenotypic and comorbid features in pediatric obsessive-compulsive disorder. Psychopathology. 2010;43: 69-78.

5. Mataix-Cols D, Nakatani E, Micali N, Heyman I. Structure of obsessivecompulsive symptoms in pediatric OCD. J Am Acad Child Adolesc Psychiatry. 2008;47:773-778.

6. Lewin AB, Bergman RL, Peris TS, Chang S, McCracken JT, Piacentini J. Correlates of insight among youth with obsessivecompulsive disorder. J Child Psychol Psychiatry. 2010;51:603-611.

7. Storch EA, Milsom VA, Merlo LJ, et al. Insight in pediatric obsessivecompulsive disorder: associations with clinical presentation. Psychiatry Res. 2008;160:212-220.

8. Flament MF, Whitacker A, Lapoport JL, et al. Obsessive compulsive disorder in adolescence: an epidemiological study. J Am Acad Child Adolesc Psychiatry. 1988;27:764-771.

9. Zohar AH. The epidemiology of obsessive-compulsive disorder in children and adolescents. Child Adolesc Psychiatr Clin N Am. 1999;8:445-460.

10. Douglass HM, Moffitt TE, Dar R, McGee R, Silva P. Obsessivecompulsive disorder in a birth cohort of 18-year-olds: prevalence and predictors. J Am Acad Child Adolesc Psychiatry. 1995;34: 1424-1431

11. Pauls DL, Alsobrook JP, Goodman W, Rasmussen S, Leckman JF. A family study of obsessive-compulsive disorder. Am J Psychiatry. 1995;152:76-84.

12. Riddle M. Obsessive-compulsive disorder in children and adolescents. Br J Psychiatry. 1998;173:91-96.

13. Piacentini J, Bergman RL. Obsessive-compulsive disorder in children. Psychiatr Clin North Am. 2000;3:519-533.

14. Barlow DH. Anxiety and its Disorders: The Nature and Treatment of Anxiety and Panic. New York, NY: Guilford Press; 2002.

15. Storch EA, Bjorgvinsson T, Riemann B, Lewin AB, Morales MJ, Murphy TK. Factors associated with poor response in cognitivebehavioral therapy for pediatric obsessive compulsive disorder. Bull Menninger Clin. 2010;74:167-185.

16. Piacentini J, Bergman RL, Keller M, McCraken J. Functional impairment in children and adolescents with obsessive-compulsive disorder. J Child Adolesc Psychopharmacol. 2003;13:S61-S69.

17. Sukhodolsky DG, do Rosario-Campos MC, Scahill L, et al. Adaptive, emotional, and family functioning of children with obsessivecompulsive disorder and comorbid attention deficit hyperactivity disorder. Am J Psychiatry. 2005;162:1125-1132.
18. Valderhaugh R, Ivarsson T. Functional impairment in clinical samples of Norwegian and Swedish children and adolescents with obsessivecompulsive disorder. Eur Child Adolesc Psychiatry. 2005;14: 164-173.

19. Lack CW, Storch EA, Keely ML, et al. Quality of life in children and adolescents with obsessive-compulsive disorder: base rates, parent-child agreement, and clinical correlates. Soc Psychiatry Psychiatr Epidemiol. 2009;44:935-942

20. Geller DA, March J; AACAP Committee on Quality Issues. Practice parameters for the assessment and treatment of children and adolescents with obsessive-compulsive disorder. J Am Acad Child Adolesc Psychiatry. 2012;51:98-113.

21. Scahill L, Riddle MA, McSwiggin-Hardin M. Children's Yale-Brown Obsessive Compulsive Scale: reliability and validity. J Am Acad Child Adolesc Psychiatry. 1997;36:844-852.

22. Bernstein GA, Victor AM, Pipal AJ, Williams KA. Comparison of clinical characteristics of pediatric autoimmune neuropsychiatric disorders associated with streptococcal infections and childhood obsessive-compulsive disorder. J Child Adolesc Psychopharmacol. 2010;20:333-340.

23. Murphy TK, Storch EA, Lewin AB, Edge PJ, Goodman WK. Clinical factors associated with pediatric autoimmune neuropsychiatric disorders associated with streptococcal infections. $J$ Pediatr. 2011;160:314-319.

24. Murphy TK, Kurlan R, Leckman J. The immunobioglogy of Tourette's disorder, pediatric autoimmune neuropsychiatric disorders associated with streptococcus and related disorders: a way forward. JChild Adolesc Psychopharmacol. 2010;20:317-331.

25. Swedo SE, Leckman JF, Rose NR. From research subgroup to clinical syndrome: Modifying the PANDAS criteria to describe PANS (pediatric acute-onset neuropsychiatric syndrome). Pediatr Therapeut. 2012;2(2)

26. Perlmutter SJ, Leitman SF, Garvey MA, et al. Therapeutic plasma exchange and intravenous immunoglobulin for obsessivecompulsive disorder and tic disorders in childhood. Lancet. 1999;354: 1153-1158

27. Snider LA, Lougee L, Slattery M, Grant P, Swedo SE. Antibiotic prophylaxis with azithromycin or penicillin for childhood-onset neuropsychiatric disorders. Biol Psychiatry. 2005;57:788-792.

28. Storch EA, Gerdes A, Adkins J, Geffken GR, Star J, Murphy TK. Behavioral treatment of child with pediatric autoimmune neuropsychiatric disorder associated with Group A streptococcal infection. $J \mathrm{Am}$ Acad Child Adolesc Psychiatry. 2004;43:510-511.

29. Storch EA, Murphy TK, Geffken GR, et al. Cognitive-behavioral therapy for PANS related obsessive-compulsive disorder: Findings from a preliminary wait-list controlled open trial. $J$ Am Acad Child Adolesc Psychiatry. 2006;45:1171-1178.

30. Abramowitz J, Whiteside SP, Deacon BJ. The effectiveness of treatment for pediatric obsessive-compulsive disorder: A meta-analysis. Behav Ther. 2005;36:55-63.

31. Watson HJ, Rees CS. Meta-analysis of randomized, controlled treatment trials for pediatric obsessive-compulsive disorder. JChild Psychol Psychiatry. 2008;49:489-498

32. Barrett P, Healy-Farrell L, March JS. Cognitive-behavioral family treatment of childhood obsessive-compulsive disorder. A controlled trial. J Am Acad Child Adolesc Psychiatry. 2004;43:46-63.

33. De Haan E, Hoogduin K, Buitelaar J, Keijsers GP. Behavior therapy versus clomipramine for the treatment of obsessive compulsive disorder in children and adolescents. $J$ Am Acad Child Adolesc Psychiatry. 1998;37:1022-1029.

34. Bergeron R, Ravindran AV, Chaput Y, et al. Sertraline and fluoxetine treatment of obsessive-compulsive disorder: results of a doubleblind, 6-month treatment study. J Clin Psychopharmacol. 2002;22: $148-154$.

35. Freeman JB, Garcia AM, Coyne L, et al. Early childhood OCD: preliminary findings from a family-based cognitive-behavioral approach. J Am Acad Child Adolesc Psychiatry. 2008;47:593-602. 
36. Pediatric OCD Treatment Study Team. Cognitive-behavioral therapy, sertraline, and their combination for children and adolescents with obsessive-compulsive disorder: the Pediatric OCD treatment study (POTS) randomized controlled trial. JAMA. 2004;292:1969-1976.

37. Piacentini J, Bergman RL, Chang S, et al. Controlled comparison of family cognitive behavioral therapy and psychoeducation/relaxation training for child obsessive-compulsive disorder. J Am Acad Child Adolesc Psychiatry. 2011;11:1149-1160.

38. March JS, Frances A, Carpenter D, Kahn DA. Expert consensus guidelines: treatment of obsessive-compulsive disorder. J Clin Psychiatry. 1997;58:S1-S72.

39. March JS, Mulle K. OCD in Children and Adolescents: A CognitiveBehavioral Treatment Manual. New York, NY: Guilford Press; 1998.

40. Valderhaug R, Larsson B, Gotestam KG, Piacentini J. An open clinical trial of cognitive-behaviour therapy in children and adolescents with obsessive-compulsive disorder administered in regular outpatient clinics. Behav Res Ther. 2007;45:577-589.

41. Choate-Summers ML, Freeman JB, Garcia AM, Coyne L, Przeworski A, Leonard HL. Clinical considerations when tailoring cognitive behavioral treatment for young children with obsessive compulsive disorder. Educ Treat Children. 2008;31:395-416.

42. Mowrer OH. Learning Theory and the Symbolic Processes. New York, NY: Wiley; 1960.

43. Mineka S, Zinbarg R. A contemporary learning theory perspective on the etiology of anxiety disorders. Am Psychol. 2006;61:10-26.

44. Storch EA, Geffken GR, Merlo LJ, et al. Family accommodation in pediatric obsessive-compulsive disorder. J Clin Child Adolesc Psychol. 2007;37:207-216.

45. Storch EA, Geffken GR, Merlo LJ, et al. Family-based cognitivebehavioral therapy for pediatric obsessive-compulsive disorder: Comparisons of intensive and weekly approaches. J Am Acad Child Adolesc Psychiatry. 2007;46:469-478.

46. Flament MF, Rapoport JL, Berg CJ, et al. Clomipramine treatment of childhood obsessive-compulsive disorder: a double-blind controlled study. Arch Gen Psychiatry. 1985;42:977-983.

47. Geller DA, Biederman J, Stewart SE, et al. Which SSRI? A metaanalysis of pharmacotherapy trials in pediatric obsessive-compulsive disorder. Am J Psychiatry. 2003;160:1919-1928.

48. Leonard HL, Swedo SE, Lenane MC. A double-blind desipramine substitution during long-term clomipramine treatment in children and adolescents with obsessive-compulsive disorder. Arch Gen Psychiatry. 1991;48:922-927.

49. March JS, Biederman J, Wolkow R, et al. Sertraline in children and adolescents with obsessive-compulsive disorder: a multicenter randomized controlled trial. JAMA. 1998;280:1752-1756.

50. Riddle MA, Reeve EA, Yaryura-Tobias JA, et al. Fluvoxamine for children and adolescents with obsessive-compulsive disorder: A randomized, controlled, multicenter trial. J Am Acad Child Adolesc Psychiatry. 2001;40:222-229.

51. Cook EH, Wagner KD, March JS, et al. Long-term sertraline treatment of children and adolescents with obsessive-compulsive disorder. J Am Acad Child Adolesc Psychiatry. 2001;40:1175-1181.

52. Geller DA, Wagner KD, Emslie G, et al. Paroxetine treatment in children and adolescents with obsessive-compulsive disorder: a randomized, multicenter, double-blind, placebo-controlled trial. J Am Acad Child Adolesc Psychiatry. 2004;43:1387-1396.

53. Liebowitz MR, Turner SM, Piacentini J, et al. Fluoxetine in children and adolescents with OCD: a placebo-controlled trial. J Am Acad Child Adolesc Psychiatry. 2002;41:1431-1438.

54. Hammad TA, Laughren T, Racoosin J. Suicidality in pediatric patients treated with antidepressant drugs. Arch Gen Psychiatry. 2006;63: 332-339.

55. Jick H, Kaye JA, Jick SS. Antidepressants and the risk of suicidal behaviors. JAMA. 2004;292:338-343.

56. Goodman WK, Murphy TK, Storch EA. Risk of adverse behavioral effects with pediatric use of antidepressants. Psychopharmacology (Berl). 2007;191:87-96.
57. Murphy TK, Segarra A, Storch EA, Goodman WK. SSRI adverse events: How to monitor and manage. Int Rev Psychiatry. 2008;20:203-208.

58. Geller DA, Hoog SL, Heiligenstein JH, et al; Fluoxetine Pediatric OCD Study Team. Fluoxetine treatment for obsessive-compulsive disorder in children and adolescents: A placebo-controlled clinical trial. J Am Acad Child Adolesc Psychiatry. 2001;40:773-779.

59. Franklin ME, Sapyta J, Freeman JB, et al. Cognitive behavior therapy augmentation of pharmacotherapy in pediatric obsessive-compulsive disorder: the Pediatric OCD Treatment Study II (POTS II) randomized controlled trial. JAMA. 2011;306:1224-1232.

60. Ravizza L, Barzega G, Bellino S, Bogetto F, Maina G. Predictors of drug treatment response in obsessive-compulsive disorder. J Clin Psychiatry. 1995;56:368-373.

61. Figueroa Y, Rosenberg DR, Birmaher B, Keshavan MS. Combination treatment with clomipramine and selective serotonin reuptake inhibitors for obsessive-compulsive disorder in children and adolescents. $J$ Child Adolesc Psychopharmacol. 1998;8:61-67.

62. McDougle CJ, Epperson CN, Pelton GH, Wasylink S, Price LH. A double-blind, placebo-controlled study of risperidone addition in serotonin reuptake inhibitor-refractory obsessive-compulsive disorder. Arch Gen Psychiatry. 2000;59:794-801.

63. McDougle CJ, Goodman WK, Leckman JF, Lee NC, Heninger GR, Price LH. Haloperidol addition in fluvoxamine-refractory obsessivecompulsive disorder: a double-blind, placebo-controlled study in patients with and without tics. Arch Gen Psychiatry. 1994;51:302-308.

64. Storch EA, Lehmkuhl H, Geffken GR, Touchton A, Murphy TK. Aripiprazole augmentation of incomplete treatment response in an adolescent male with obsessive-compulsive disorder. Depress Anxiety. 2008;25:172-174.

65. Grant P, Lougee L, Hirschtritt M, Swedo SE. An open-label trial of riluzole, a glutamate antagonist, in children with treatment-resistant obsessive-compulsive disorder. J Child Adolesc Psychopharmacol. 2007; 17:761-767.

66. Bloch MH, Landeros-Weisenberger A, Kelmendi B, Coric V, Bracken MB, Leckman JF. A systematic review: antipsychotic augmentation with treatment refractory obsessive-compulsive disorder. Mol Psychiatry. 2006;11:622-632.

67. Erzegovesi S, Cavallini MC, Cavedini P, Diaferia G, Locatelli M, Bellodi L. Clinical predictors of drug response in obsessive-compulsive disorder. J Clin Psychopharmacol. 2001;21:488-492.

68. Lewin AB, Storch EA, Storch HD. Risks from antipsychotic medications in children and adolescents. JAMA. 2010;303:729-730.

69. Amir N, Freshman M, Foa EB. Family distress and involvement in relatives of obsessive-compulsive disorder patients. J Anxiety Disord. 2000;14:209-217.

70. Steketee G, Van Noppen B. Family approaches to treatment for obsessive compulsive disorder. Rev Bras Psiquiatr. 2003;25:43-50. Portuguese.

71. Garcia AM, Sapyta JJ, Moore PS, et al. Predictors and moderators of treatment outcome in the Pediatric Obsessive Compulsive Treatment Study (POTS I). J Am Acad Child Adolesc Psychiatry. 2010;49: 1024-1033.

72. Ginsburg GS, Kingery JN, Drake KL, Grados MA. Predictors of treatment response in pediatric obsessive-compulsive disorder. J Am Acad Child Adolesc Psychiatry. 2008;40:868-878.

73. Storch EA, Larson MJ, Muroff J, et al. Predictors of functional impairment in pediatric obsessive-compulsive disorder. $J$ Anxiety Disord. 2010;48:275-283.

74. Catapanos F, Sperandeo R, Perris F, Lanzaro M, Maj M. Insight and resistance in patients with obsessive-compulsive disorder. Psychopathology. 2001;34:62-68.

75. Shetti CN, Reddy YC, Kandavel T, et al. Clinical predictors of drug nonresponse in obsessive-compulsive disorder. J Clin Psychiatry. 2005;66: $1517-1523$.

76. Merlo LJ, Storch EA, Lehmkuhl HD, et al. Cognitive behavioral therapy plus motivational interviewing improves outcome for pediatric obsessive-compulsive disorder: a preliminary study. Cogn Behav Ther. 2010;39:24-27. 
77. Langley AK, Lewin AB, Bergman RL, Lee JC, Piacentini J. Correlates of comorbid anxiety and externalizing disorders in childhood obsessive-compulsive disorder. Eur Child Adolesc Psychiatry. 2010;19: 637-645.

78. Storch EA, Larson MJ, Merlo LJ, et al. Comorbidity of pediatric obsessive-compulsive disorder and anxiety disorders: impact on symptom severity and impairment. J Psychopathol Behav Assess. 2007;30:111-120.

79. Walitza S, Melfsen S, Jans T, Zellmann H, Wewetzer C, Warnke A. Obsessive-compulsive disorder in children and adolescents. Dtsch Arztebl Int. 2011;108:173-179.

80. Himle JA, Fischer DJ, Van Etten ML, Janeck AS, Hanna GL. Group behavioral therapy for adolescents with tic-related and non-tic-related obsessive-compulsive disorder. Depress Anxiety. 2003;17:73-77.

81. March JS, Franklin ME, Leonard H, et al. Tics moderate treatment outcome with sertraline but not cognitive-behavioral therapy in pediatric obsessive compulsive disorder. Biol Psychiatry. 2007;61:344-347.

82. Storch EA, Merlo LJ, Larson MJ, et al. Impact of comorbidity on cognitive-behavioral therapy response in pediatric obsessivecompulsive disorder. J Am Acad Child Adolesc Psychiatry. 2008;47: 583-592.

83. Geller DA, Biederman J, Stewart SE, et al. Impact of comorbidity on treatment response to paroxetine in pediatric obsessive-compulsive disorder: is the use of exclusion criteria empirically supported in randomized clinical trials? J Child Adolesc Psychopharmacol. 2003;13: S19-S29.
84. Masi G, Millepiedi S, Perugi G, et al. Pharmacotherapy in paediatric obsessive-compulsive disorder: a naturalistic, retrospective study. CNS Drugs. 2009;23:241-252.

85. Rapee RM. The influence of comorbidity on treatment outcome for children and adolescents with anxiety disorders. Behav Res Ther. 2003;41:105-112.

86. Feldman J, Kazdin AE. Parent management training for oppositional and conduct problem children. Clin Psychol. 1995;48:3-5.

87. Gentile S. Efficacy of antidepressant medications in children and and adolescents with obsessive-compulsive disorder: a systematic appraisal. J Clin Psychopharmacol. 2011;31:625-632.

88. American Academy of Child and Adolescent Psychiatry. Practice parameters for the assessment and treatment of children and adolescents with attention-deficit/hyperactivity disorder. J Am Acad Child Adolesc Psychiatry. 2007;46:894-921.

89. Blanco C, Olfson M, Stein DJ, Simpson HB, Gameroff MJ, Narrow WH. Treatment of obsessive-compulsive disorder by US psychiatrists. J Clin Psychiatry. 2006;6:946-951.

90. Williams TI, Salkovskis PM, Forrester L, Turner S, White H, Allsopp MA. A randomised controlled trial of cognitive behavioural treatment for obsessive compulsive disorder in children and adolescents. Eur Child Adolesc Psychiatry. 2010;19:449-456.

91. De Veaugh-Geiss J, Moroz G, Biederman J, et al. Clomipramine hydrochloride in childhood and adolescent obsessive compulsive disorder: A multicenter trial. J Am Acad Child Adolesc Psychiatry. 1998;31:45-49.

\section{Publish your work in this journal}

Pediatric Health, Medicine and Therapeutics is an international, peerreviewed, open access journal publishing original research, reports, editorials, reviews and commentaries. All aspects of health maintenance, preventative measures and disease treatment interventions are addressed within the journal. Practitioners from all disciplines are invited to submit

\section{Dovepress}

their work as well as healthcare researchers and patient support groups The manuscript management system is completely online and includes a very quick and fair peer-review system. Visit http://www.dovepress. com/testimonials.php to read real quotes from published authors. 